GEORGETOWN SCIENTIFIC RESEARCH JOURNAL
Volume Two Edition One Fall 2021

\title{
Energy Security in Poland: Where the Energy Sector Falls Short and Where It Can Go
}

Ariyand Amnipour 


\title{
Energy Security in Poland: Where the Energy Sector Falls Short and Where It Can Go
}

\author{
Ariyand Amnipour \\ Department of Biology, Georgetown University, Washington, D.C. \\ Email: ama412@georgetown.edu \\ https://doi.org/10.48091/gsr.v2i1.26
}

\begin{abstract}
In the aftermath of World War II, Poland rebuilt its energy sector through the use of fossil fuels, thus establishing a dependence on coal power. This reliance has slowed its transition to environmentally friendly energy sources, leading to increased greenhouse gas emissions. These characteristics of Poland's energy sector serve as a roadblock to diversifying the nation's energy sources and have subsequently resulted in its average energy security and poor environmental sustainability rankings in the top 25 largest on the 2020 International Index of Energy Security Risk. This ranking highlights the areas of improvement necessary for the nation to achieve greater energy security. This paper outlines Poland's current energy security status and provides policy recommendations that the nation's federal government can employ to improve overall energy security by diversifying their energy sources and improving the environmental impact of the energy sector.
\end{abstract}

Keywords: Poland, Energy Security, Policy

\section{Introduction}

Following World War II, Poland's economy and infrastructure had been devastated due to warfare raged across the country. The country had been ravaged physically and economically, leading to a period of modernization and rebuilding. This period created a dependence on coal that is still central to the country's energy sector today. ${ }^{1}$ During the $20^{\text {th }}$ century, coal-burning plants and factories contributed to the rebuilding of the nation's economy. However, the economically favorable outcome of coal reliance has stifled Poland's transition to cleaner energy sources in the $21^{\text {st }}$ century. ${ }^{1}$ Poland's energy security, determined by reliability, affordability, and environmental impact of energy sources, ${ }^{2}$ has been negatively affected by its reservations about transitioning to cleaner energy sources. A lack of progress in energy diversification, along with coal's prominence as a part of Poland's energy supply and economy, have contributed to the country's current energy security status and its energy security rating compared to other nations. ${ }^{3,4}$

\section{Energy Security Assessment}

According to the 2020 International Index of Energy Security Risk, Poland ranked $11^{\text {th }}$ in the world for coal consumption and $10^{\text {th }}$ for coal production. $^{3}$ As of 2020, coal makes up $48 \%$ of Poland's current energy mix and 79\% of Poland's power generation mix of energy sources. ${ }^{3}$ Energy mix is defined as the combination of direct energy use, while power generation mix is defined as the combination of energy sources used to generate electricity. Coal contributed to the largest percentages of Poland's current energy mix and power generation mix. ${ }^{3}$ Comparatively, natural gas makes up $16 \%$ of the country's energy mix and $7 \%$ 
of the nation's power generation mix. ${ }^{3}$ Nuclear energy did not contribute to Poland's energy mix or power generation mix. ${ }^{3}$ Moreover, Poland, as of 2018, was a net importer of petroleum, natural gas, and coal, showing dependence on foreign energy supplies. ${ }^{3}$ These factors contributed to Poland's energy security risk score of 967 on the 2020 International Index of Energy Security Risk evaluation. ${ }^{3}$ Comparatively, the Organization for Economic Co-operation and Development (OECD) had a group average score of $884 .^{3}$ To give more context to Poland's energy security risk score, Poland's score ranked $12^{\text {th }}$ out of 25 scores associated with countries considered "large energy users". ${ }^{3}$

Poland has also been evaluated by the World Energy Council and assigned a trilemma score, which is an evaluation of the energy security, energy equity, and environmental stability of a country scored on an A through D scale. Poland scored a trilemma score of 70.4 out of 100 , with a rating of a $\mathrm{B}$ in energy security, a $\mathrm{B}$ in energy equity, and a $\mathrm{C}$ in environmental sustainability. ${ }^{4}$

Polish energy security ranked $37^{\text {th }}$ out of 101 countries due to its import dependence, lack of electricity generation diversity, and energy storage capacity. ${ }^{4}$ Between 2010 and 2020, Polish import dependence has been trending towards more importation, which is a threat to energy security because foreign suppliers have control over energy supply and access. ${ }^{4}$ Diversification of electricity generation was the nation's second-lowest key metric score, well below 35 out of 100, with 100 being the highest level of possible diversification of energy in a country. ${ }^{4}$ These metrics are determined relative to the other nations' ranking and evaluation. ${ }^{4}$ Due to Poland's reliance on coal for power generation, there is limited use of renewable energy sources, natural gas, and nuclear power. ${ }^{3}$ Energy storage capacity was found to be below 50 out of 100, which indicates a need for improvement because the country relies heavily on new production or importation of energy, as compared to relying on readily available stores. All three of these scores factored into an overall energy security score of 62.7 out of $100 .{ }^{4}$

The energy equity of the country, which is defined by accessibility and affordability, was an obvious strength of their energy sector at 84.7 out of 100. This metric explains Poland's relatively higher trilemma score, as well as its $\mathrm{B}$ grade in energy equity. ${ }^{4}$ As of 2020 , Poland scored a $100 \%$ in access to electricity, demonstrating that an overwhelming majority of citizens have access to electricity. ${ }^{4}$ Electricity prices also scored in the 90 s, which shows electricity is provided at affordable prices to the population. ${ }^{4}$ However, this affordability is almost overshadowed by the nation's environmental stability performance; the country ranked $63^{\text {rd }}$ out of 108 countries with a score of 65.9 out of 100 in environmental sustainability. ${ }^{4} \mathrm{~A}$ major indicator of its poor score is its low metric of electricity generation from decarbonized sources; this is by far Poland's lowest key indicator score, falling below $25 .{ }^{4}$ This metric contributes to Poland's C rating in environmental sustainability. ${ }^{4}$

\section{Domestic Energy Ambitions}

Poland is currently trying to implement policies that increase energy security through domestic energy initiatives and transitions to cleaner energy sources..$^{5}$ This can be seen in the federal government's plans of Poland's Energy Policy by 2030 (PEP2030), which has since been updated to PEP2040. ${ }^{6}$

PEP2040, officially released in 2020, plans to reduce coal reliance by cutting the fuel from $80 \%$ to $60 \%$ of the national power generation mix; this will then be followed by an ambitious decline to $22 \%$ by $2040 .^{6}$ This reduction in coal reliance is fueled by planned investment in new energy sources such as nuclear energy. The Ministry of Energy expects to have six new nuclear plants producing domestic energy, with the first being launched in 2033; each subsequent plant will launch every two years until 2043 to produce a total capacity of 6-9 Gigawatts. ${ }^{7}$ The government plans to roll out Generation III and III+ nuclear plants, which they claim will still supply affordable energy 
to citizens. ${ }^{7}$ Generation $\mathrm{III}$ and $\mathrm{III}+$ plants are nuclear plants that have safety envelopes constructed on Western safety standards and require relatively large electric grids. ${ }^{7}$ Generation III power plants have reactor technology that give them the potential to function for upwards of 60 years. ${ }^{8}$ This transition towards nuclear energy can be seen as a long-term goal of creating energy security because it diversifies Poland's energy mix while also moving the country away from coal reliance. Since nuclear energy is currently not contributing to Poland's energy or power generation mix, this would be a large step for Poland in achieving more energy security through diversification. ${ }^{3}$

Additionally, nuclear power development would contribute to the environmental sustainability aspect of energy security because nuclear power is notably cleaner than coal; a coal plant on average will put out 704 to $709 \mathrm{~kg}$ of sulfur dioxide per Gigawatt hour (GWh), 717-721kg of nitrous oxides per $\mathrm{GWh}$, and $150 \mathrm{~kg}$ of dust per GWh. ${ }^{9}$ According to PEP2040A, a nuclear plant will emit zero air pollutants through the technology of Generation III and III+ reactors. ${ }^{7}$ Nuclear plants, however, create high, intermediate, and low-level radioactive waste that must be properly contained and managed through compaction. ${ }^{9}$ Radioactive waste is not a significant safety concern because Generation III and III+ reactors are regulated by the Nuclear Regulatory Commission and equipped with technology that allows them to run safely for approximately 60 years. ${ }^{8}$ Radioactive waste is not a negative tradeoff of nuclear energy because Poland's future reactors are expected to represent about $10 \%$ of energy generation, which will be more environmentally friendly than coal. ${ }^{7}$ The government claims nuclear energy will be Poland's main strategy for reducing greenhouse gas emissions while also allowing the country to diversify their energy mix, thus increasing their energy security. ${ }^{7}$

PEP2040 plans to reduce Poland's emissions by $30 \%$ by 2030 , in comparison to its 1990 emission levels, with a mixture of investments in renewables and natural gas. Nuclear energy is its largest investment to reduce emissions. ${ }^{7}$ This progression towards ambitious environmental sustainability is a relatively new development. Poland's reliance on coal has led it to shy away from accepting legally binding carbon emission reduction plans, as seen in 2015 when Poland vetoed an amendment to the Kyoto Protocol, an international treaty between state parties that promotes actions to address climate change and reduce greenhouse gas emissions through the United Nations Framework Convention on Climate Change. ${ }^{11,12}$ The amendment tried to set "a legal framework for carbon emission reductions" that would remain in place until 2020 and the European Union's (EU's) entry into the Paris Climate Agreement. ${ }^{11}$ Poland refused until 2018, when they ratified the amendment. ${ }^{11}$ In 2019, Poland was also left out of a EU 2050 climate agreement, which looked to push states to climate neutrality by $2050 .{ }^{13}$ Poland was steadfast against coming to terms with the agreement due to worries over financing their nuclear energy transition, claiming that Poland would reach climate neutrality at its own pace; the country even mentioned the idea of reaching neutrality by $2070 .{ }^{13}$ The outcomes of this negotiation are part of the important context surrounding the slowmoving progression towards a more environmentally sustainable future, as funding and EU assistance becomes key to pushing Poland towards their nuclear diversification goals.

The PEP2040 plan is an ambitious target by Poland, but feelings of uncertainty linger with respect to when it will be achieved. These fears are fueled by the political moves and stances taken by the Polish government, outlined in the previous paragraph, which illustrate the government is not taking on legally binding actions to meet these goals. Nonetheless, Poland promises that the nation will achieve this PEP2040 plan. However, the pace at which it does seems uncertain. Poland's inability to deliver is underscored by the overambitious PEP2030 plan, published in 2009, which needed to be amended in 2019 to extend the 
country's deadline to meet the stated goals to $2040 .^{7}$ This need to delay dates by a decade throws into question if the nation will meet its own deadlines once again. These fears must be addressed, and ambitions realized to ensure that Poland moves toward joining the rest of the EU in reducing emissions through energy diversification before the devastating impacts of climate change become irreversible.

\section{Policy Recommendations}

Moving forward, Poland's citizens need to call on their government to move towards environmental sustainability and diversification of energy supply. These are important aspects of energy security that can create assurance of more reliable domestic energy for Poland's citizens. In 2009, Poland's citizens and those of other European nations suffered blackouts and energy shortages due to a dispute between a Russian gas company, Gazprom, and Ukraine, as the two fought over pricing of Russian gas exported through Ukraine. ${ }^{14}$ As Poland looks to diversify to cleaner energy sources, their strategy, one shared by many members of the EU, serves to offer a large benefit to the country; diversification will move the nation away from a heavy dependence on one exporter and allow for less devastation in the future if the reliability of one energy source is diminished. In the wake of the 2009 shutdown, these countries should seek to move away from Russian energy export dependence, diversify their energy suppliers, and build up domestic sources in an attempt to improve energy security and avoid future blackouts due to foreign disputes. ${ }^{14}$

One policy recommendation that Poland and its citizens should support is investment in the Energy Bridge Project between Ukraine and Poland. The Energy Bridge will connect Poland to Ukraine across their shared border to create a new nuclear energy supply from the Ukrainian stateowned utility company, Energoatom. ${ }^{15}$ The project will connect Energoatom's Khmelnitsky nuclear plant, supplying Poland with nuclear generated electricity that can help the country as they transition away from coal, allowing for greater diversification of energy in Poland. ${ }^{15}$ Nuclear is also clean energy that will allow for greater cuts in emissions as the country moves away from coal. ${ }^{9}$ Utilizing Ukrainian nuclear energy can help Poland move away from coal faster, moving them closer to the EU goal of carbon neutrality by 2050 . Ukraine has a demonstrated history of trade with Poland, which has contributed to the fact that in 2017 and 2018 Poland was Ukraine's second largest economic exportation market, with a trade value of approximately $\$ 2,727,594$ and $\$ 3,257,236$ USD respectively .10 Due to this interconnectedness through trade, the Polish government may see Ukraine as a more reliable partner than Russia, one which Poland can work with in the future.

Poland's government should also invest in carbon capture and sequestration technology. This would increase the energy security of Poland because carbon capture would reduce the number of emissions that the country's coal sector produces, thus making the energy source less environmentally harmful. Specifically, the country should invest in post-combustion carbon capture. The use of post-combustion capture is a technology that allows for fossil fuel-fired power plants to reduce emissions by separating the gas products of the coal energy production and sequestering the carbon dioxide that would usually be released into the atmosphere. ${ }^{16}$ Implementation of this technology in existing plants is necessary because Poland is expected to be carbon neutral after 2050 due to its coal dependence, but carboncapture could speed up that process and improve relations between the member state and the EU. ${ }^{13}$ Carbon-capture may be an expensive solution, but the EU might be willing to help fund the initiative if that means Poland will reach its 2050 goal.

\section{Conclusion}

Poland has much work to do to improve its energy security, as indicated by the Global Energy Institute's and the World Energy Council's evaluations. The Polish government's lack of 
movement in 2015 towards legally binding protocols to reduce greenhouse gas emissions through the Kyoto Protocol is a glaring sign that the government is not doing as much as it can, in terms of improving energy security through environmental sustainability. Poland needs to rejoin Europe in its action towards fighting climate change because Poland is currently moving at its own pace, as demonstrated by its refusal to sign on to the 2050 carbon neutrality agreement, unlike its closest EU allies. In addition, by delivering on the PEP2040 ambitions, such as through the development of Poland's nuclear power sector, the country will move towards diversification and more self-sufficiency. Therefore, meeting these goals without further delay or setbacks is imperative to improve Poland's energy security.

In conclusion, diversification and environmental stability are the two aspects of Poland's energy sector that require improvement. Movement away from Russian fuel and towards Ukrainian nuclear energy is a cleaner and more secure option. Additionally, post-combustion capture would make coal plants more environmentally friendly while Poland transitions from coal to nuclear power and other energy sources, thereby improving its overall energy security.

\section{References}

1. Hockenos, P. (2020). As Pressures Mount, Poland's Once-Mighty Coal Industry Is in Retreat. Yale E360. https://e360.yale.edu/features/as-pressuresmount-polands-once-mighty-coal-industry-is-inretreat.

2. Sabonis-Helf, T. 2020. "Energy Security and Strategy Lecture." October.

3. Global Energy Institute. (2020). International Index of Energy Security Risk. https://www.globalenergyinstitute.org/sites/default /files/2020-04/iesri-report 2020420 20.pdf.

4. World Energy Council. (2020). WEC Trilemma: Country Profile. https://trilemma.worldenergy.org/\#!/countryprofile? country=United\%20Kingdom\&year $=2020$.

5. Barteczko, A. (2020). Poland to Accelerate Coal Phase-out, Spend Billions on Renewable and
Nuclear Energy. Reuters.

https://www.reuters.com/article/us-poland-coalidUSKBN25Z1G3.

6. International Trade Administration. (2019).

Poland's Energy Strategy by 2040.

http://www.trade.gov/market-

intelligence/polands-energy-strategy-2040.

7. Ministry of Energy. (2019). Energy Policy of Poland Unt... - Poland - Climate Change Laws of the World. https://climate-

laws.org/geographies/poland/policies/energypolicy-of-poland-until-2030-and-2040-pep-2030and-pep-2040.

8. Goldberg, S. M. \& Posner, R. 2011. Nuclear Reactors: Generation to Generation. Nuclear Reactors, 40.

9. Rashad, S. M, \& Hammad, F. H. (2000). Nuclear Power and the Environment: Comparative Assessment of Environmental and Health Impacts of Electricity-Generating Systems. Applied Energy, 65 (1), 211-29. https://doi.org/10.1016/S03062619(99)00069-0.

10. World Bank. (n.d.). Ukraine Exports by country and region 2018 | WITS Data. Retrieved November 18, 2021, from

https://wits.worldbank.org/CountryProfile/en/Cou ntry/UKR/Year/2018/TradeFlow/Export

11. Zulinski, J. (2018). Poland's Transition to a Cleaner Economy Article.

https://www.eesi.org/articles/view/polandstransition-to-a-cleaner-economy.

12. United Nations. (n.d.). What is the Kyoto Protocol? | UNFCCC. Retrieved November 18, 2021, from https://unfccc.int/kyoto_protocol

13. Baczynska, J., Strupczewski, G. (2019). EU Leaves Poland out of 2050 Climate Deal after Standoff. Reuters. https://www.reuters.com/article/usclimate-change-eu-idUSKBN1YG01I.

14. Reed, S. (2019). Burned by Russia, Poland Turns to U.S. for Natural Gas and Energy Security - The New York Times.

https://www.nytimes.com/2019/02/26/business/po land-gas-lng-russia-usa.html.

15. Hersh, M., \& Kee, E. (2018). What Role Can Energy Bridge Play in Ukraine's Energy Resilience? Atlantic Council.

https://www.atlanticcouncil.org/blogs/energysourc e/what-role-can-energy-bridge-play-in-ukraine-senergy-resilience/. 
16. Lockwood, T. (2017). A Comparative Review of Next-Generation Carbon Capture Technologies for Coal-Fired Power Plant. Energy Procedia, 13th International Conference on Greenhouse Gas Control Technologies, 14-18 (114), 2658-70. https://doi.org/10.1016/j.egypro.2017.03.1850. 


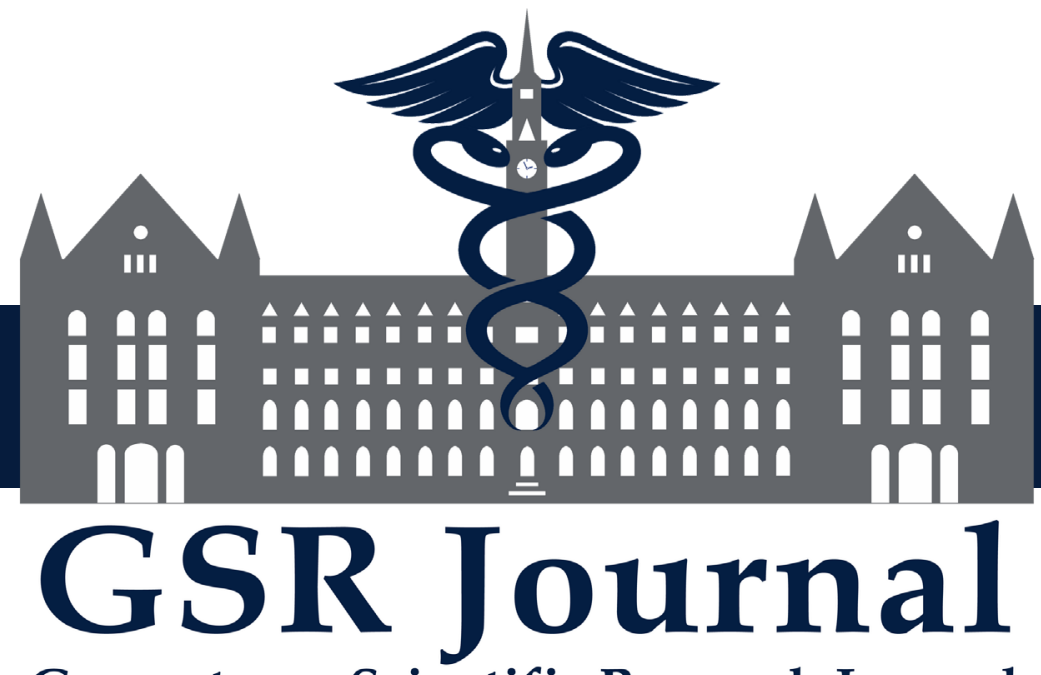

Georgetown Scientific Research Journal 